\title{
Transport of Manure-borne Testosterone in Soils Affected by Artificial Rainfall Events
}

\author{
Yong $\mathrm{Qi}^{\mathrm{a}}$ and Tian C. Zhang ${ }^{\mathrm{b}}$
}

${ }^{a}$ Post-doc and corresponding author, 136 PKI, Civil Engineering Dept., University of Nebraska-Lincoln, Omaha, NE 68182, USA. E-mail: yqi01@ unomaha.edu; ' Professor, 205D PKI, Civil Engineering Dept., University of Nebraska-Lincoln, Omaha, NE 68182, USA.

\begin{abstract}
Information is very limited on fate and transport of steroidal hormones in soils. In this study, the rainfall simulation tests were conducted with a soil slab reactor to investigate the transport of manure-borne testosterone in a silty-clay loam soil under six controllable operation conditions (i.e., three rainfall intensities and two tillage practices). The properties [e.g., rainwater volume, particle size distribution (PSD)] of the slurry samples collected in runoff and leachate at different time intervals were measured; their correlation with the distribution of testosterone among runoff, leachate and soil matrix was analyzed. The results indicated that more than $88 \%$ of the testosterone was held by the applied manure and/or soil matrix even under the rainfall intensity of 100-year return frequency. The runoff facilitated testosterone transport through both dissolved and particle-associated phases, with the corresponding mass ratio being $\sim 7$ to 3 . Soil particles collected through runoff were mainly silt-sized aggregates (STA) and clays, indicating the necessity of using partially-dispersed soil particles as testing materials to conduct batch tests (e.g., sorption/desorption). No testosterone was detected at the soil depth $>20 \mathrm{~cm}$ or in the leachate samples, indicating that transport of testosterone through the soil is very slow when there is no preferential flow. Tillage practice could impede the transport of testosterone in runoff. For the first time, results and the methodologies of this study allow one to quantify the hormone distribution among runoff, leachate and soil matrix at the same time and to obtain a comprehensive picture of the F/T of manure-borne testosterone in soil-water environments.
\end{abstract}

Keywords: Testosterone; Rainfall simulation; Transport; Runoff; Leachate 


\section{$1 \quad$ Introduction}

In the U.S., there are about 238,000 animal feeding operations, many of them are concentrated animal feeding operations (CAFOs). These CAFOs generate more than 500 million tons of animal waste annually (USEPA 2001), and the majority of the manure from CAFOs is applied to agricultural land, leading to the risk of natural and synthetic hormones in CAFO wastes entering the environment (Kolpin et al., 2002; Bhandari et al., 2009; Webster et al., 2012). These hormones have been of an increasing concern due to their ability to alter the sexual behavior and endocrine systems of animals and aquatic species even at a very low concentration (as low as 1 ng/L) (Teles et al., 2004; D'Alessio et al., 2014). Hormones and their metabolites have been found in cattle waste with significant concentrations, in runoff from CAFOs, and in $\sim 40 \%$ of the 139 streams sampled across 30 states in the U.S. (Kolpin et al., 2002). Being persistent in the soil (Finlay-Moore et al., 2000; Schiffer et al., 2001) and lipophilic with most of their $\log \mathrm{K}_{\mathrm{ow}}$ being 2.6-4.0 (Lai et al., 2002; Schiffer et al., 2004; Khanal et al., 2006), most steroid hormones are expected to be sorbed on soils/organic matter, and thus, are unlikely to be very mobile. However, this expectation cannot explain the frequent detection of hormones in ground and surface water. For example, testosterone was detected in the soil sampled from 45-m deep below a dairy-farm wastewater lagoon (Shai et al., 2008).

Column studies have been conducted to investigate the non-equilibrium sorption, vertical transport and degradation of hormones in soils. The results of column studies identified a significant mass loss of hormones due to sorption and degradation; most hormones were retained in the first several inches of the soil column, indicating a low potential for the hormone leaching through the soils (Das et al., 2004). Schiffer et al (2004) studied the transport of trenbolone and melengestrol acetate in a soil column. They found that dissolved organic carbon (DOC)-hormone 
associates might lead the hormone to be more or less mobile, depending on the DOC affinity to the soil. It was reported that $17 \beta$-estradiol and testosterone placed on the soil surface contaminated groundwater via preferential flow as demonstrated in a column study (Sangsupan et al., 2006). However, in these soil column studies, water was pumped directly to the surface of the soil columns; therefore, the interaction between water and soil surface was not as intense as that in the real world rainfall events. In addition, in order to obtain the breakthrough point quickly, the hydraulic loading rates were unreasonably high (e.g., the hydraulic loading of one test was more than two times of the average annual precipitation in the Mid-west of the U.S.) to make the water penetrate through the columns less than 12 mins; the preferential flow might exist along the edge of the column. These drawbacks may lead to a misunderstanding of the transport of hormone through the soils. In addition, these columns could not generate information on surface runoff.

Field study is a direct way to understand the fate and transport (F/T) of manure-borne steroidal hormones in soils. Van Donk et al. (2013) conducted a four-year field study to investigate the potential contamination of groundwater from manure-borne hormones. They monitored the leaching of steroidal hormones at the bottom of 73.2-cm deep percolation lysimeters installed in plots treated with beef cattle manure, and detected the steroid hormones in only 5\% of the leachate samples. Mansell et al. (2011) detected steroid hormones in the runoff in both filtered (dissolved) and particle-associated phases, which indicated the potential mechanism of particle- or colloid-facilitated transport of hormones through runoff. However, field studies often involve complicated situations (e.g., uncontrollable rainfall events, involvement of a large number of test plots, difficulty in sampling runoff and leachate simultaneously and in detection of micro-pollutants, unpredictable contaminant sources). Dutta et al. (2010) conducted the study 
on the transport of free and conjugated estrogen in surface runoff from poultry litter-amended soil. They found that the organic matters played very important roles during the transport of estrogen through runoff; no-tillage practice resulted in a lower export of estrogens with surface runoff. Due to the difference in soil types (e.g., texture, composition) and climate conditions, the results of previous field studies often are location-based or need special interpretation (e.g., only applied to specific type of soils and rainfall events), and thus, have not be able to provide a comprehensive picture about the F/T of hormones in soil environments. Therefore, it is imperative to develop a new methodology for conducting rainfall simulation tests in a consistent way and under controllable conditions so that the contribution of runoff, leachate, and soil matrix to the distribution and $\mathrm{F} / \mathrm{T}$ of hormones can be determined simultaneously.

In nature, soils contain a wide range of particles with different particle size distributions (PSDs) and different mobility during rainfall events. It was reported that over $80 \%$ of the total soil particles found in storm water runoff were less than $20 \mu \mathrm{m}$ (Randall 1982; Furumai et al., 2002). Previous studies indicated that the sorption and desorption of pesticide and hormones associated with soil particles were highly particle-size dependent (Wang and Keller 2008; Qi et al., 2014). Furthermore, total organic carbon (TOC) in the soil was also reported to be a critical factor that would affect the F/T of hormones in soils (Sarmah et al., 2008; Gineys et al., 2012). Sarmah et al. (2008) studied the sorption of 17 $\beta$-estradiol (E2) and 17 $\alpha$-ethynylestradiol (EE2) on six selected soils with batch reactors. They found that the sorption capacity of the soil was attributed to both surface area and soil organic carbon content. Therefore, the properties (e.g., soil particle size, TOC content) of runoff and leachate and their contribution to the distribution and $\mathrm{F} / \mathrm{T}$ of manure-borne hormones should be investigated. 
The goal of this study was to use a lab-scale soil slab reactor to investigate the transport of hormones in soil environments via rainfall simulation tests. The specific objectives were to: 1 ) investigate the properties (e.g., PSD, TOC) of soil-water samples taken away by runoff and leachate; 2) determine the manure-borne hormone distribution among runoff, leachate and soil matrix under six different conditions (i.e., rainfall intensity, tillage practices); and 3) evaluate the correlation between the properties of the soil-water samples and the hormones' F/T in soils.

\section{Materials and Methods}

\section{$2.1 \quad$ Manure and Hormone Spiking}

Testosterone was selected as the representative hormone because 1) it can transform to other metabolites, and it is a prototype for other synthetic androgenic hormones (Kanayama and Pope 2012); 2) little is known about the F/T of androgenic hormones (Casey et al., 2004); and 3) it was used previously (Qi et al., 2014; Qi and Zhang 2015a; Ma et al., 2015). Stockpiled female manure was sampled from the feedlot (CAFO) owned by the Haskell Agricultural Laboratory (HAL, Concord, NE, USA) at the University of Nebraska-Lincoln (UNL). The testosterone concentration in the female and male mixed manure was $\sim 5.8 \mathrm{ng} / \mathrm{g}$ (Van Donk et al., 2013), but no testosterone was in the female manure sampled in this study. Once in the laboratory, the manure was packed in aluminum foil, sterilized with an autoclave (Mol. \# 10985, Market Forge Co. New York City, USA) at the temperature of $121{ }^{\circ} \mathrm{C}$ for $30 \mathrm{~min}$ to eliminate the possible testosterone biodegradation by the microorganisms (Berns et al., 2008), and then dried at $40{ }^{\circ} \mathrm{C}$ for $24 \mathrm{~h}$. This sterilized and dried manure $(3.5 \mathrm{~g})$ was then mixed with $3.5 \mathrm{~mL}$ of the $10 \mu \mathrm{g} / \mathrm{L}$ testosterone stock solution (including $0.3 \mu \mathrm{g} / \mathrm{L}$ of ${ }^{14} \mathrm{C}$-labeled and $9.7 \mu \mathrm{g} / \mathrm{L}$ of unlabeled testosterone) to make testosterone-spiked slurry of $10 \mathrm{ng} / \mathrm{g}$ testosterone. Then, the slurry of the 
testosterone-spiked manure was put in a 50-mL glass centrifuge tube (\#0553841A, Fisher

Scientific, Inc. USA) and rotated (top to bottom, $360^{\circ} / 5 \mathrm{~s}$ ) for $24 \mathrm{~h}$ and dried in the oven at $40{ }^{\circ} \mathrm{C}$.

Then the testosterone-spiked manure was mashed to powder (in order to spread on the soil surface evenly) with the ceramic masher and ready for applying to the soil slab reactor.

\subsection{Soil, Soil Slab Reactor and Manure Application}

The HAL soil was selected because it could be obtained together with manure samples from the CAFO at HAL and was used in the previous studies (Qi et al., 2014; Ma et al., 2015). The top $0-15,15-30 \mathrm{~cm}(0-6,6-12$ inch $)$ of the field soils were collected separately. The measured bulk density of the intact field soil was $1.32 \mathrm{~g} / \mathrm{mL}$ (Table S1 in Supplementary Materials). The soil field slope was approximately $8 \%$, and the soil had the permeability in the range of $15-50 \mathrm{~mm} / \mathrm{hr}$ and the available water holding capacity of $0.17-0.22 \mathrm{~mm} / \mathrm{mm}$ (USDA, 1978). The HAL soil (Nora silty clay loam, fine-silty, mixed, mesic Udic Haplustolls) contains 0.95\% total organic carbon (TOC). The total $\mathrm{Fe}, \mathrm{Cu}, \mathrm{Ca}, \mathrm{Mg}$ are 21, 4.7, 2131, $318 \mathrm{mg} / \mathrm{kg}$, respectively. The cation exchange capacity (CEC) of the HAL soil is $13.9 \mathrm{meq} / 100 \mathrm{~g}$. No residual testosterone was detected in the soil samples (Ma et al., 2015).

As shown in Fig. 1, the soil slab $(36 \mathrm{~cm} \times 36 \mathrm{~cm})$ was placed into a container. Two rectangle glass boxes (each $\mathrm{L} \times \mathrm{W} \times \mathrm{H}=20.32 \mathrm{~cm} \times 7.62 \mathrm{~cm} \times 7.62 \mathrm{~cm}$, see Fig. $\mathrm{S} 2$ of Supplementary Materials) (no sorption to hormones) were inserted into the soil for creating two test areas. Two PVC pipes on the soil surface with a $7.62 \mathrm{~cm}$ (3-inch) wide slot linking the glass boxes to collect runoff from each of the two test areas. To collect leachate, another two rectangle glass trays (each $\mathrm{L} \times \mathrm{H} \times \mathrm{W}=20.32 \mathrm{~cm} \times 7.62 \mathrm{~cm} \times 2.54 \mathrm{~cm}$, see Fig. S2) connected with flexible pipes are inserted into the soil at the bottom right below the area of the top two glass boundaries (Fig. S2). In order to eliminate the possible biodegradation due to the microorganism 
in the soil, the soils and glass plates were repacked in the aluminum foil and sterilized with the autoclave at the temperature of $121{ }^{\circ} \mathrm{C}$ for $30 \mathrm{~min}$ (Berns et al., 2008). The sterilized HAL soils were sequentially repacked in the soil slab reactor according to the density of the soil and massvolume method (details are shown in Supplementary Materials).

According to the nutrient requirement of corn in Nebraska, the applied manure was 75 tons/acre (Koelsch et al., 2003). Therefore, $3.5 \mathrm{~g}$ dried manure containing $10 \mathrm{ng} / \mathrm{g}$ spikedtestosterone was spread evenly to the soil surface of each test area $(20.32 \mathrm{~cm} \times 7.62 \mathrm{~cm})$ of the soil slab reactor. The soil slab reactor was ready for the rainfall simulation tests if no-tillage agricultural practice was to be tested. To simulate the agricultural tillage practice, after directly spreading $3.5 \mathrm{~g}$ dried manure containing $10 \mathrm{ng} / \mathrm{g}$ spiked-testosterone on the soil surface, a 5-cm (2-inch) masher (\#84387, Potato masher, Bradshaw Inc. Rancho Cucamonga, CA, USA) was used to till the top 5-cm soils to mix the spiked-testosterone manure with the soils completely.

\subsection{Artificial Rain System and Rainfall Simulation Tests}

The artificial rain system consisted of a bucket $(30 \mathrm{~cm}$ in diameter and $30 \mathrm{~cm}$ height) containing tap water, a peristaltic pump (Model\# 755050, Barnant Co. Barrington, IL, USA) with five pump heads and rollers, five pump tubes, and five same water distribution devices set up $2.44 \mathrm{~m}$ (8-ft) above the soil slab reactor (Fig. S1). The water distribution system (e.g., pipes, water distribution devices) was cleaned (disinfected) by washing with $70 \%$ (v/v) alcohol first and then 3 times with the tap water.

The rainfall intensity was controlled under 2, 10, 100 years return frequency with the rainfall intensity of 25.2, 39.2, $61.0 \mathrm{~mm} / \mathrm{h}$ (Table 1$)$, respectively. The rainfall intensity (I) corresponded to Area 2 and was calculated as $I=A /(t+B)$, where A, B are constants that depend on the return period and climatic factors; and t is rainfall duration (Wischmeier and Smith 1978). 
Six different test conditions were conducted independently (Table 1). All of the rainfall events were run 2 hours or longer. The runoff and leachate samples were collected starting from the time when the first drop of the sample came out, with the time intervals of $0-5,5-10,10-30$, 30-60, 60-90, 90-120,> $120 \mathrm{~min}$.

After each of the rainfall simulation test, soil cores were sampled from three locations (upslope, middle and downslope, shown in Fig. S2) in each test area with sharp-edge plastic pipes (3/4-inch in diameter). One (1.0) gram of the soil sampled from 0, 10, $20 \mathrm{~cm}$ of the soil slab, which was obtained from the collected soil core column proportionally due to the compression in the sampling process, was used to analyze the total mass of hormone in the soil (and the concentration in the liquid and solid phase) (see Supplementary Materials for details) . After the soil core sampling, all the soil in the box was removed and replaced with the new sterilized soil for the next test condition.

\subsection{Analytical Methods}

The properties, e.g. volume, TOC, transported soil weight (TSW), PSD, of the runoff and leachate were analyzed. The radiolabeled testosterone was used successfully to analyze the testosterone concentration in the samples in the literatures (Casey et al., 2004; Sangsupan et al., 2006) and our previous studies (Qi et al., 2014; Qi and Zhang, 2015a). In this study, the testosterone concentrations of the collected samples in runoff and leachate of each time interval were detected before and after centrifugation of $4000 \mathrm{rpm}$ for $45 \mathrm{~min}$, which could be used to determine the distribution of testosterone in the dissolved- and particle-associated phase (Qi and Zhang, 2015b). After centrifugation, $1 \mathrm{~mL}$ of the sample supernatant was pipetted to a $20 \mathrm{~mL}$ counting vial (Wheaton Millville, New Jersey, USA) with 10 mL cocktail (\#6013179, Ultima Gold $^{\mathrm{TM}}$ F, PerkinElmer, Waltham, MA, USA) to detect the radioactivity with 2500 TR Liquid 
Scintillation Counter (LSC, Packard, Downers Grove, IL, USA). The testosterone sorbed onto the soil particles could be determined by comparing the radioactivity before and after centrifugation.

All of the runoff and leachate samples were wet-sieved with the sieve of $200 \#(0.75 \mu \mathrm{m})$ to determine the weight of sand-sized aggregates (SDA). Then, the PSD of the soil slurry supernatant was analyzed with a particle size analyzer (NanoBrook 90Plus/BI-MAS, Brookhaven Instrument Co. Holtsville, NY). The PSD of the soil slurry was evaluated with both fully- and partially-dispersed methods as per the procedures shown in previous study (Qi and Zhang 2015b). All of the radioactivity detections were based on three blank samples (without hormone) of centrifuge tubes that had the same analytical conditions (e.g., sample, cocktail volume) as testing tubes.

\section{$3 \quad$ Results and Discussion}

\subsection{Rainfall Properties and Occurrence Time of Runoff and Leachate}

The average diameter size of the artificial raindrop was $6.7 \mathrm{~mm}$ with the calculated terminal velocity of $6.4 \mathrm{~m} / \mathrm{s}$ (Guo 2011) (Table S2). As shown in Table 1, it takes much longer time to collect the leachate sample than the runoff's under all operation conditions; high rainfall intensity takes shorter time to generate runoff and leachate than that with low rainfall intensity. With tillage, the time required to collect runoff is longer, while it takes shorter time to collect leachate than no tillage practice.

\subsection{Rainwater, TOC, Transported Soil Weight and Particle Size Distribution}

The total rainwater volume loaded to each of the test areas was 780, 1213 and $1890 \mathrm{~mL}$ under the rainfall intensity of 2,10 and 100 years return frequency, respectively, during the 
rainfall events. Fig. 2 shows the rainwater volume of the samples collected in runoff and leachate under six different operation conditions. Table 2 shows the rainwater distribution among runoff, leachate and soil matrix under different operation conditions. With tillage, a higher fraction of the rainwater penetrates through the soil and shows up as leachate, while runoff takes a higher fraction of the rainwater when there is no tillage. For example, for NT10 (no tillage and 10 years return frequency), $375 \mathrm{~mL}$ and $273 \mathrm{~mL}$ of rainwater goes to runoff and leachate, respectively in 2 $\mathrm{h}$, and that is $323 \mathrm{~mL}$ and $325 \mathrm{~mL}$, respectively with T10 (tillage and 10 years return frequency) (Table 2). In addition, higher intensity rainfall events generate a higher percent volume of runoff than leachate.

TOC in the soil was reported to be a critical factor that would affect the F/T of hormones in soils (Sarmah et al., 2008; Gineys et al., 2012). TOC of the samples was measured in order to find the correlation between TOC and transported testosterone. As shown in Fig. 3, TOC in the runoff is much higher than that in the corresponding leachate, indicating a higher potential for runoff to facilitate the transport of hormones. Fig. 3 shows that the TOC concentration of the samples collected during the first $30 \mathrm{~min}$ is much higher than that of the samples collected after $30 \mathrm{~min}$, especially when higher rainfall intensity is used. This might be because higher rainfall intensity has stronger dispersion power, leading to the release of the organic matter from both the soil matrix and the applied manure. As shown in Fig. 3 and Fig. 6, the trend of TOC concentration in runoff was consistent with the testosterone concentration in runoff, indicating organic matter has a higher potential to facilitate the transport of testosterone due to its higher sorption affinity.

Being lipophilic with most of their $\log \mathrm{K}_{\mathrm{ow}}$ being 2.6-4.0 (Lai et al., 2002; Schiffer et al., 2004; Khanal et al., 2006), most steroid hormones are expected to be sorbed onto soil particles. 
Previous studies indicate the sorption of hormone to soil particles is particle-size dependent (Qi et al., 2014; Qi and Zhang 2015a; Qi et al., 2015). Therefore, the TSW and PSD of the soil particles in runoff and leachate are very important to understand how they will facilitate the transport of manure-borne hormones. Fig. 4 shows that the TSW concentration of the runoff samples collected from the first 30 min are much higher than that of the samples collected after 30 min. During the first $30 \mathrm{~min}$, the TSW concentration of the collected samples with tillage was much higher than that of the samples collected without tillage. However, after 30 min, the TSW concentration of the runoff samples collected with and without tillage was very close for each of the rainfall events. Even though the TSW concentration of the samples collected with tillage practice was much higher than that of the corresponding samples of no tillage practice, the TSW of tillage and non-tillage was not significantly different (Table 2), which was due to the higher sample volume of runoff of non-tillage practice.

Effective diameter represents the average size of the particles in the collected samples, which reflects the PSD of the soil particles taken away through runoff and leachate. After wet sieving with the sieve of No. $200(0.75 \mu \mathrm{m})$, no sand particles were found in the runoff or leachate (data not shown). This might be because: 1) the HAL soil is a silty-clay loam with less than 6\% of sand existed in the bulk soil (Qi and Zhang 2015b); and 2) no big rill was formed during the rainfall events, leading to a low possibility of sand motion. As shown in Fig. 5, for these six rainfall events, the effective diameter was less than $2.5 \mu \mathrm{m}$, which is consistent with the report that over $80 \%$ of the total soil particles found in storm water runoff were less than $20 \mu \mathrm{m}$ (Randall, 1982; Furumai et al., 2002). Fig. 5 shows that the effective diameter of the particles taken away by the runoff of the first $30 \mathrm{~min}$ is much bigger than that of the samples collected after $30 \mathrm{~min}$. Also, bigger particles are taken away by the runoff with tillage compared to that of 
no tillage. The PSD of soil particles taken away in runoff was also evaluated through the fullydispersed methods [i.e., adding sodium hexametaphosphate $\left(\mathrm{NaPO}_{3}\right)_{6}$ and high-speed stirring to separate the soil particles to their primary states] (Qi and Zhang 2015b). The results showed that the effective diameter evaluated through the fully-dispersed method was much smaller than that of the partially-dispersed method (Qi and Zhang, 2015b), indicating that part of the fine particles were taken away in an aggregate form. This conclusion is consistent with the previous study, i.e., many soil aggregates are stable under the force of erosion (Young 1980). In nature, the dispersion processes (e.g., soil erosion during storm events) are relatively mild, and these soil particles of DSFs are mixed together in the form of aggregates (i.e., partially-dispersed soil particles). Furthermore, soil particles bigger than $50 \mathrm{~nm}$ were not detected in the leachate sample even under the rainfall intensity of 100 years return frequency (data not shown). Therefore, there is a low potential for leachate to facilitate the transport of hormones through particle-associated phase into groundwater if there is no preferential flow in the subsurface.

\subsection{Testosterone Distribution among Runoff, Leachate and Soil Matrix}

The testosterone concentration of the runoff taken away in the first 30 min was much higher than that of the samples collected after 30 min (Fig. 6), which was consistent with the results of the TOC and the total mass of the soil particles (Figs. 3 and 4). The testosterone concentration in the collected runoff samples without tillage was much higher than that with tillage practice. This might be because, without tillage, the manure-containing testosterone was exposed on the surface of the soil, and it was much easier for the rain water to take away the released testosterone and the manure to the runoff samples.

Table 3 shows the testosterone taken away by runoff for each rainfall event, which is the sum of the runoff samples of each time interval calculated with the testosterone concentration 
(Fig. 6) and the corresponding sample volume (Fig. 2). As shown in Table 3, without tillage, the testosterone taken away through runoff is $0.63,1.29$, and $3.93 \mathrm{ng}$ under the rainfall intensity of 2 , 10 , and 100 years return frequency, respectively, while it is $0.48,0.95,2.90 \mathrm{ng}$, respectively with tillage. Therefore, higher rainfall intensity and no tillage facilitate more testosterone transport through runoff. As shown in Fig. S3, within all of the rainfall events, no testosterone was detected in the soil sampled from the depth of $20 \mathrm{~cm}$, and no testosterone was detected in the samples collected through leachate (Table 3), which leads to the conclusion that no testosterone could penetrate through the 20 -cm thick silty-clay loam layer within the $\sim 2$-h rainfall event. This conclusion is consistent with the study reported by Mansell and Drewes (2004), i.e., the mobility of the hormones in subsurface systems was low; neither estriol nor testosterone was detected in groundwater monitoring wells or shallow lysimeters representing water samples after $1.5 \mathrm{~m}$ of travel through porous media.

\subsection{Transported Testosterone Distribution in the Dissolved and Particle-Associated Phases}

Fig. 6 shows that the testosterone concentrations in runoff with and without centrifugation are significantly different, which is attributed to the testosterone sorbed onto the soil particles that would settle down with the centrifugation force. Therefore, the testosterone taken away through runoff could be separated as dissolved and particle-associated phases. The transport of testosterone by dissolved phase was $\sim 70 \%$ of the total mass of testosterone taken

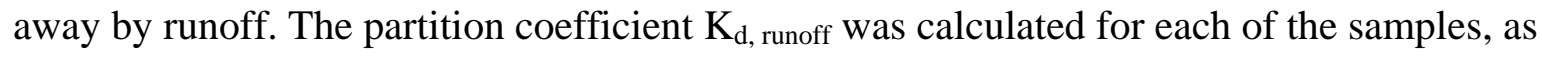
shown in Table S3. The $K_{d \text {, runoff }}$ ranges from 6 to $20 \mathrm{~L} / \mathrm{kg}$ for all the runoff samples, while the linear sorption coefficient of the bulk soil in batch tests, $\mathrm{K}_{\mathrm{d}}$ was $79.9 \mathrm{~L} / \mathrm{kg}$ (Qi and Zhang, 2015b). The large difference between $\mathrm{K}_{\mathrm{d} \text {, runoff }}$ and $\mathrm{K}_{\mathrm{d}}$ might be because: 1) the soil/water ratio of the samples in the runoff (being 30-60 g soil/L water, Table S3) was much higher than that (i.e., 20 
$\mathrm{g} / \mathrm{L}$ ) used in the batch tests. The previous tests showed that the higher soil/water ratio would impede the sorption of testosterone to soil particles (Qi and Zhang 2015a) and thus lead to a lower $\mathrm{K}_{\mathrm{d} \text {, runoff }}$ value; and 2) during the rainfall events, the sorption of the testosterone (i.e., released by the manure) to the soil particles (i.e., taken away in runoff) did not reach equilibrium when these samples were collected.

Table 3 and Fig. 7 show the testosterone mass distribution between the dissolved and particle-associated phases in the soil slurry samples collected in runoff. Fig. 7 shows that more than $50 \%$ of the hormone transported through the liquid phase for all these six operation conditions. This information is very important to understand comprehensively the mechanism and pathway of how the manure-borne hormone would transport in runoff during different rainfall events. Also, this information could be used to predict the transport of hormones in runoff when the soil erosion and sorption information are available.

\subsection{Implications and Limitations}

The results indicated that the applied manure and soil matrix held more than $88.8 \%$ of the testosterone even under the 100-year return frequency of no tillage (NT100 in Table 3). The runoff facilitated the transport of testosterone through both dissolved and particle-associated phases with the corresponding mass ratio being $\sim 7$ to 3 (e.g., 0.44/0.19 for NT2 in Table 3).

Results of this study indicate that the soil particles collected through runoff were mainly siltsized aggregates (STA) and clays. No testosterone was detected in the leachate samples, indicating that the potential should be very low for testosterone to transport through the soil slab if there is no preferential flow.

The intensity of a normal rainfall event is not as strong as that of 100 -year return frequency and the duration is usually less than 2 hours, which means the transport of hormone in 
runoff should be very limited. In addition, the half-life of testosterone is $\sim 5$ hours under the aerobic condition and $\sim 27$ hours under the anaerobic condition with the degradation of testosterone by the manure-borne bacteria (Yang et al., 2010). From this study, the manure-borne testosterone taken away in runoff was less than $12 \%$, and no testosterone was found in the soil at a depth $>20 \mathrm{~cm}$ after one rainfall event even at the rainfall intensity of 100-year return frequency. Therefore, the chance for manure-borne testosterone to transport to surface water and penetrate into deeper soil, or stay in a long period may be very low. Therefore, the contamination of manure-borne hormones from CAFOs to the soil and groundwater might not be of a great concern. However, in this study, results of the transported manure-borne testosterone in runoff and leachate were obtained just under one single rainfall event; there might be more testosterone transported in runoff under intermittent rainfall events. Therefore, further studies should be conducted to understand the accumulated testosterone transport in runoff and leachate under the influence of continual rainfall events.

This study has some limitations. The biodegradation and transformation of testosterone in soils were not investigated in this study, and only one type of hormone was investigated. This was because the study dealt with environmentally-relevant hormone concentrations. In order to make the results more specified and simplify the experiment as well as consider the limit of test instrument, transformation of the hormone during the rainfall events was not considered as well. The properties of testosterone metabolites and other steroidal hormones might be different, further study should be conducted to determine their F/T in the rainfall events.

Nevertheless, this study, for the first time, quantitatively analyzes the transport of manure-borne hormone in soil environments under controllable conditions, and the hormone distribution among runoff, leachate and soil matrix were quantitatively determined at the same 
time, which provided a comprehensive picture of the F/T of manure-borne testosterone in soils. The methodology for rainfall simulation tests developed in this study could be used to study other pollutants (e.g., pesticides, nutrients) in soils. The information provided in this study is also important to understand the soil erosion process and how such a process would facilitate the transport of micro-pollutants in soil environments.

\section{Conclusion}

In light of the above analysis, the following conclusions could be made:

1) The runoff facilitates the transport of testosterone through both dissolved and particleassociated phases with the corresponding mass ratio being $\sim 7$ to 3 ;

2) More than $88 \%$ of the testosterone is held by the applied manure and soil matrix even under rainfall events with a 100-year return frequency;

3) Tillage practice will impede the transport of testosterone through runoff;

4) It is difficult for the leachate to facilitate the transport of testosterone through the soil slab when there is no preferential flow; and The soil particles transported through runoff are particle-size-related and are in the aggregate form. Thus, it is necessary for one to study hormones associated with soil particles of DSFs based on the partially-dispersed method in sorption-desorption tests.

\section{$5 \quad$ Acknowledgements}

The authors would like to thanks Drs. Mamo, Kranz and Shapiro at the HAL and Dr. Bartelt-Hunt in the Civil Engineering Department of University of Nebraska-Lincoln (UNL) for 
providing soil samples and technical support. The research was made possible through support from the U.S. National Science Foundation (NSF Award \#:1067537).

\section{References}

Berns, A. E., Philipp, H., Narres, H., Burauel, P., Vereecken, H., Tappe, W. 2008. Effect of Gamma-Sterilization and Autoclaving on Soil Organic Matter Structure as Studied by Solid State NMR, UV and Fluorescence Spectroscopy. Eur. J. Soil Sci., 59(3), 540-550.

Bhandari, A., Surampalli, R., Adams, C. D., Champagne, P., Ong, S. K., Tyagi, R. D., Zhang, T. C. 2009. Contaminants of Emerging Environmental Concern, ASCE, Reston, Virginia, U.S.

Casey, F. X. M., Hakk, H., Simunek, J., Larsen, G. L. 2004. Fate and Transport of Testosterone in Agricultural Soils. Environ. Sci. Technol., 38(3), 790-798.

D'Alessio, M., Vasudevan, D., Lichwa, J., Mohanty, S. K., Ray, C. 2014. Fate and Transport of Selected Estrogen Compounds in Hawaii Soils: Effect of Soil Type and Macropores. J. Contam. Hydrol., 166(1), 1-10.

Das, B. S., Lee, L. S., Rao, P. S. C., Hultgren, R. P. 2004. Sorption and Degradation of Steroid Hormones in Soils during Transport: Column Studies and Model Evaluation. Environ. Sci. Technol., 38(5), 1460-1470.

Dutta, S., Inamdar, S., Tso, J., Aga, D. S., Sims, J. T. 2010. Free and Conjugated Estrogen Exports in Surface-runoff from Poultry Litter-amended Soil. J. Environ. Qual., 39(5), 1688-1698.

Finlay-Moore, O., Hartel, P. G., Cabrera, M. L. 2000. 17 Beta-Estradiol and Testosterone in Soil and Runoff from Grasslands Amended with Broiler Litter. J. Environ. Qual., 29(5), 1604-1611.

Furumai, H., Balmer, H., Boller, M. 2002. Dynamic Behavior of Suspended Pollutants and Particle Size Distribution in Highway Runoff. Water Sci. Technol., 46(11-12), 413-418.

Gineys, N., Giroud, B., Gineys, M., Vulliet, E. 2012. Retention of Selected Steroids on a SiltLoam Soil. J. Environ. Sci. Health Part A-Toxic/Hazard. Subst. Environ. Eng., 47(13), 2133-2140.

Guo, J. K. 2011. Motion of Spheres Falling through Fluids. J. Hydraul. Res., 49(1), 32-41.

Kanayama, G., and Pope, H. G. 2012. Illicit use of Androgens and Other Hormones: Recent Advances. Curr Opin Endocrinol Diabetes Obes, 19(3), 211-219. 
Khanal, S. K., Xie, B., Thompson, M. L., Sung, S., Ong, S. K., Van, L. J. 2006. Fate, Transport, and Biodegradation of Natural Estrogens in the Environment and Engineered Systems. Environ. Sci. Technol., 40(21), 6537-6546.

Koelsch, R., Shapiro, C., Deloughery, R. 2003. Nebraska's CNMP: Manure Application Workbook. EC03-720, University of Nebraska Cooperative Extension, Lincoln, Nebraska.

Kolpin, D., Furlong, E., Meyer, M., Thurman, E., Zaugg, S., Barber, L., Buxton, H. 2002. Pharmaceuticals, Hormones, and Other Organic Wastewater Contaminants in US Streams, 1999-2000: A National Reconnaissance. Environ. Sci. Technol., 36(6), $1202-1211$.

Lai, K. M., Scrimshaw, M. D., Lester, J. N. 2002. Prediction of the Bioaccumulation Factors and Body Burden of Natural and Synthetic Estrogens in Aquatic Organisms in the River Systems. Sci. Total Environ., 289(1-3), 159-168.

Ma, R., Zhang, T. C., Bartelt-Hunt, S. L., Qi, Y., Kranz, B., Snow, D., Mader, T., Shapiro, C., Shelton, D. P., Donk, S. V., Tarkalson, D., Ensley, S. 2015. Influence of Soil Properties and Test Conditions on Sorption and Desorption of Testosterone. J. Environ. Eng., 10.1061/ (ASCE) EE.1943-7870.0000937 1-9.

Mansell, D. S., Bryson, R. J., Harter, T., Webster, E. P., Kolodziej, E. P., David, L. S. 2011. Fate of Endogenous Steroid Hormones in Steer Feedlots Under Simulated Rainfall-Induced Runoff. Environ. Sci. Technol., 45(20), 8811-8818.

Mansell, B., and Drewes, J. 2004. Fate of Steroidal Hormones during Soil-Aquifer Treatment. Ground Water Monit. Remediat., 24(2), 94-101.

Qi, Y., and Zhang, T. C. 2015a. Sorption and Desorption of Testosterone at Environmentally relevant Levels: Effects of Aquatic Conditions and Soil Particle Size Fractions. J. Environ. Eng., DOI: 10.1061/ (ASCE) EE.1943-7870.0001001, 1-9.

Qi, Y., and Zhang, T. C. 2015b. Effects of Partially-Dispersed Soil Particles of Different Size Fractions on Sorption of Hormones: Methodology and Implications. Water Research, under $3^{\text {rd }}$ review.

Qi, Y., Zhang, T.C., Ma, R. (2015). Properties of soil particle size fractions and their contribution on fate and transport of hormones in soil environment. Emerging MicroPollutants in the Environment: Occurrence, Fate, and Distribution, ACS Symposium Series, Volume 1198. DOI: 10.1021/bk-2015-1198.ch004, 75-96.

Qi, Y., Zhang, T. C., Ren, Y. Z. 2014. Testosterone Sorption and Desorption: Effects of Soil Particle Size. J. Hazard. Mater., 279(30), 493-501. 
Randall, C. W., Randall, C. W., Stormwater Detention Ponds for Water Quality Control., 1982. In Stormwater Detention Facilities Planning, Design, Operation and Maintenance. New York: American Society of Civil Engineers

Sangsupan, H. A., Radcliffe, D. E., Hartel, P. G., Jenkins, M. B., Vencill, W. K., Cabrera, M. L. 2006. Sorption and Transport of 17 Beta-Estradiol and Testosterone in Undisturbed Soil Columns. J. Environ. Qual., 35(6), 2261-2272.

Sarmah, A. K., Northcott, G. L., Scherr, F. F. 2008. Retention of Estrogenic Steroid Hormones by Selected New Zealand Soils. Environ. Int., 34(6), 749-755.

Schiffer, B., Totsche, K. U., Jann, S., Kogel-Knabner, I., Meyer, K., Meyer, H. H. D. 2004. Mobility of the Growth Promoters Trenbolone and Melengestrol Acetate in Agricultural Soil: Column Studies. Sci. Total Environ., 326(1-3), 225-237.

Schiffer, B., Daxenberger, A., Meyer, K., Meyer, H. 2001. The Fate of Trenbolone Acetate and Melengestrol Acetate After Application as Growth Promoters in Cattle: Environmental Studies. Environ. Health Perspect., 109(11), 1145-1151.

Shai, A., Ofer, D., Sara, E., Keren, C., Irena, P., Amit, G., Zeev, R., Shahar, B., Laurence, S. S. 2008. Transport of Testosterone and Estrogen from Dairy-Farm Waste Lagoons to Groundwater. Environ. Sci. Technol., 42(15), 5521-5526.

Teles, M., Gravato, C., Pacheco, M., Santos, M. A. 2004. Juvenile Sea Bass Biotransformation, Genotoxic and Endocrine Responses to Beta-Naphthoflavone, 4-Nonylphenol and 17 Beta-Estradiol Individual and Combined Exposures. Chemosphere, 57(2), 147-158.

USEPA. 2001. Economic Analysis for the Proposed Revisions to the National Pollutant Discharge Elimination System Regulation and the Effluent Guidelines for Concentration Animal Feeding Operations. Engineering and Analysis Division, EPA821-R-01-001.

Van Donk, S. J., Biswas, S., Kranz, W. L., Snow, D. D., Bartelt-Hunt, S. L., Mader, T. L., Shapiro, C. A., Shelton, D. P., Tarkalson, D. D., Zhang, T. C., Ensley, S. 2013. Transport of Steroid Hormones in the Vadose Zone After Land Application of Beef Cattle Manure. Trans. ASABE, 56(4), 1327-1338.

Wang, P., and Keller, A. A. 2008. Particle-Size Dependent Sorption and Desorption of Pesticides within a Water-Soil-Nonionic Surfactant System. Environ. Sci. Technol., 42(9), 3381-3387.

Webster, J. P., Kover, S. C., Bryson, R. J., Harter, T., Mansell, D. S., Sedlak, D. L., Kolodziej, E. P. 2012. Occurrence of Trenbolone Acetate Metabolites in Simulated Confined Animal Feeding Operation (CAFO) Runoff. Environ. Sci. Technol., 46(7), 3803-3810.

Wischmeier, W. H., and Smith, D. D. 1978. Predicting Rainfall Erosion Losses. USDA Agr. Handbook 537. 
Yang, Y. Y., Borch, T., Young, R. B., Goodridge, L. D., Davis J. G. 2010. Degradation Kinetics of Testosterone by Manure-Borne Bacteria: Influence of Temperature, $\mathrm{pH}$, Glucose Amendments, and Dissolved Oxygen. J. Environ. Qual. 39(4), 1153-1160.

Young, R. A. 1980. Characteristics of Eroded Sediment. Transactions of the ASAE, 23(5), 1139-1142. 
1 Table 1. Test conditions and corresponding occurrence time of runoff and leachate

\begin{tabular}{lccccccc}
\hline & \multicolumn{9}{c}{ Test Conditions } & \multicolumn{2}{c}{ Time needed (min) } \\
\cline { 3 - 4 } Test ID \# & $\begin{array}{c}\text { Tillage } \\
\text { Practice }\end{array}$ & $\begin{array}{c}\text { Return } \\
\text { Frequency }(\mathrm{yr})\end{array}$ & $\begin{array}{c}\text { Intensity } \\
(\mathrm{mm} / \mathrm{hr})^{\mathrm{a}}\end{array}$ & $\begin{array}{c}\text { Pump rate } \\
(\mathrm{mL} / \mathrm{min})^{\mathrm{b}}\end{array}$ & & Runoff & Leachate \\
\hline NT2 & & 2 & 25.2 & 30 & 39 & 70 \\
NT10 & No tillage & 10 & 39.2 & 47 & 25 & 38 \\
NT100 & & 100 & 61.0 & 75 & 7 & 26 \\
\hline T2 & & 2 & 25.2 & 30 & 45 & 62 \\
T10 & Tillage & 10 & 39.2 & 47 & 31 & 42 \\
T100 & & 100 & 61.0 & 75 & 12 & 22 \\
\hline
\end{tabular}

$2{ }^{a}$ Calculated as I $=\mathrm{A} /(\mathrm{t}+\mathrm{B})$ of Area 2 , where $\mathrm{A}, \mathrm{B}$ are constants that depend on the return period 3 and climatic factors, $\mathrm{t}=$ duration (Wischmeier and Smith 1978); ${ }^{\mathrm{b}}$ Pump rate of each head, and 4 five heads were used.

5

6 Table 2. Results of rainfall simulation tests under different rainfall events

\begin{tabular}{lccccccc}
\hline \multirow{2}{*}{ Test ID \# } & \multicolumn{3}{c}{ Rainwater $(\mathrm{mL})^{\mathrm{a}}$} & \multicolumn{2}{c}{ TOC $(\mathrm{mg})^{\mathrm{b}}$} & \multicolumn{2}{c}{ TSW $^{(\mathrm{g})^{\mathrm{c}}}$} \\
& Runoff & Leach. & Soil & Runoff & Leach. & Runoff & Leach. \\
\hline NT2 & 195 & 198 & 388 & 0.93 & 0.77 & 5.15 & 0 \\
NT10 & 375 & 273 & 566 & 1.18 & 0.82 & 12.08 & 0 \\
NT100 & 863 & 602 & 426 & 2.79 & 1.46 & 35.34 & 0 \\
T2 & 225 & 210 & 345 & 1.15 & 0.88 & 7.14 & 0 \\
T10 & 323 & 325 & 566 & 1.53 & 1.15 & 11.84 & 0 \\
T100 & 713 & 665 & 513 & 3.39 & 2.13 & 35.01 & 0 \\
\hline
\end{tabular}

7 The rainwater volume distribution was calculated based on Fig. 2 by adding the volume of the 8 samples generated through all the time intervals and by mass balance based on the total water 9 volume loaded to each of the test areas. ${ }^{\mathrm{b}}$ The mass of TOC was calculated with the concentration 10 of Fig. 3 and the corresponding sample volume of Fig. 2; ${ }^{\mathrm{c}}$ The transported soil weight (TSW) 11 was calculated with the concentration in Fig. 4 and the corresponding sample volume in Fig. 2. 
13 Table 3. Manure-borne testosterone distribution among runoff, leachate and soil matrix

\begin{tabular}{ccccccc}
\hline \multirow{2}{*}{$\begin{array}{c}\text { Operation } \\
\text { Conditions }\end{array}$} & $\begin{array}{c}\text { Dissolved } \\
(\mathrm{ng})^{\mathrm{a}}\end{array}$ & $\begin{array}{c}\text { Particle-Associated } \\
(\mathrm{ng})^{\mathrm{b}}\end{array}$ & $\begin{array}{c}\text { Total } \\
(\mathrm{ng})^{\mathrm{c}}\end{array}$ & $\begin{array}{c}\text { Percent } \\
(\%)^{\mathrm{d}}\end{array}$ & $\begin{array}{c}\text { Soil } \\
\text { Matrix } \\
(\mathrm{ng})^{\mathrm{e}}\end{array}$ & $\begin{array}{c}\text { Leachate } \\
(\mathrm{ng})\end{array}$ \\
\hline NT2 & 0.44 & 0.19 & 0.63 & 1.80 & 34.37 & 0 \\
NT10 & 0.90 & 0.40 & 1.29 & 3.70 & 34.52 & 0 \\
NT100 & 2.49 & 1.44 & 3.93 & 11.21 & 33.71 & 0 \\
T2 & 0.36 & 0.12 & 0.48 & 1.36 & 34.05 & 0 \\
T10 & 0.67 & 0.28 & 0.95 & 2.72 & 31.07 & 0 \\
T100 & 1.99 & 0.92 & 2.90 & 8.30 & 32.10 & 0 \\
\hline
\end{tabular}

14 a The mass of testosterone was calculated with the concentration in Figure 6 after centrifugation

15 with the collected sample volume in Fig. 2 ; ${ }^{\mathrm{b}} \mathrm{Calculated}$ from Fig. 6 and mass balance: Particle-

16 Associated $=$ Total testosterone of the slurry sample - Dissolved testosterone in the liquid;

$17{ }^{\mathrm{c}}$ Testosterone taken away by runoff; ${ }^{\mathrm{d}} 1.8 \%=0.63 / 35$ (the total mass of testosterone applied to

18 each of the testing area $=3.5 \mathrm{~g} \times 10 \mathrm{ng} / \mathrm{g}$ ); ${ }^{\mathrm{e}} 35 \mathrm{ng}-$ total testosterone taken away by runoff and

19 leachate. 


\section{Figure 1}

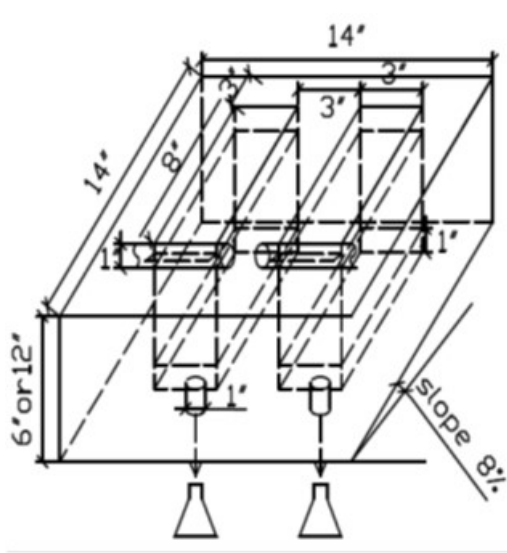

(a)

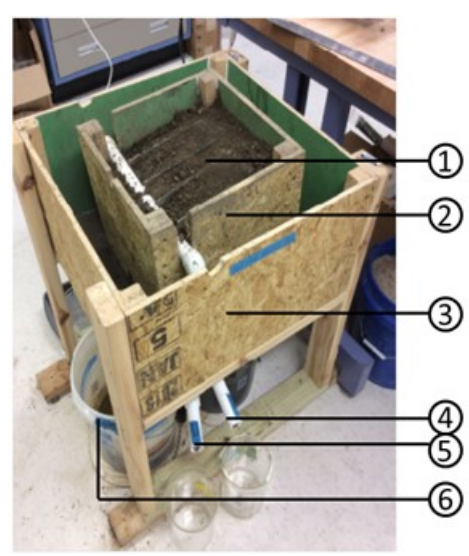

(b)

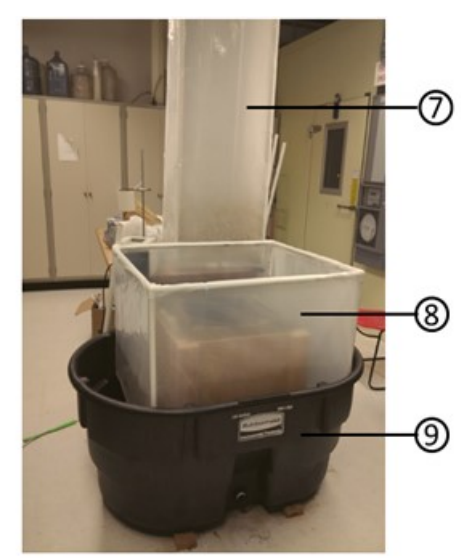

(c)

Figure 1. Schematic diagram of the soil slab reactor (a). Samples are collected from both runoff and leachate (b). The artificial rain is generated by a system (consisting of a tank, peristaltic pump, timer, tubes, valves, etc., shown in Fig. S1) and distributed via a high resistance distribution system placed $2.44 \mathrm{~m}(8-\mathrm{ft})$ above the soil slab reactor $(\mathrm{c})$. 1-Runoff collection glass box; 2-Soil slab box; 3-Supporting frame; 4-Leachate collection pipe; 5-Runoff collection pipe; 6-Overflow container; 7-Rainfall generator; 8-Spill out protection film; 9-Contamination protection tank. See Figs S1 and $\mathrm{S} 2$ in Supplementary Materials for additional information. 


\section{Figure 2}
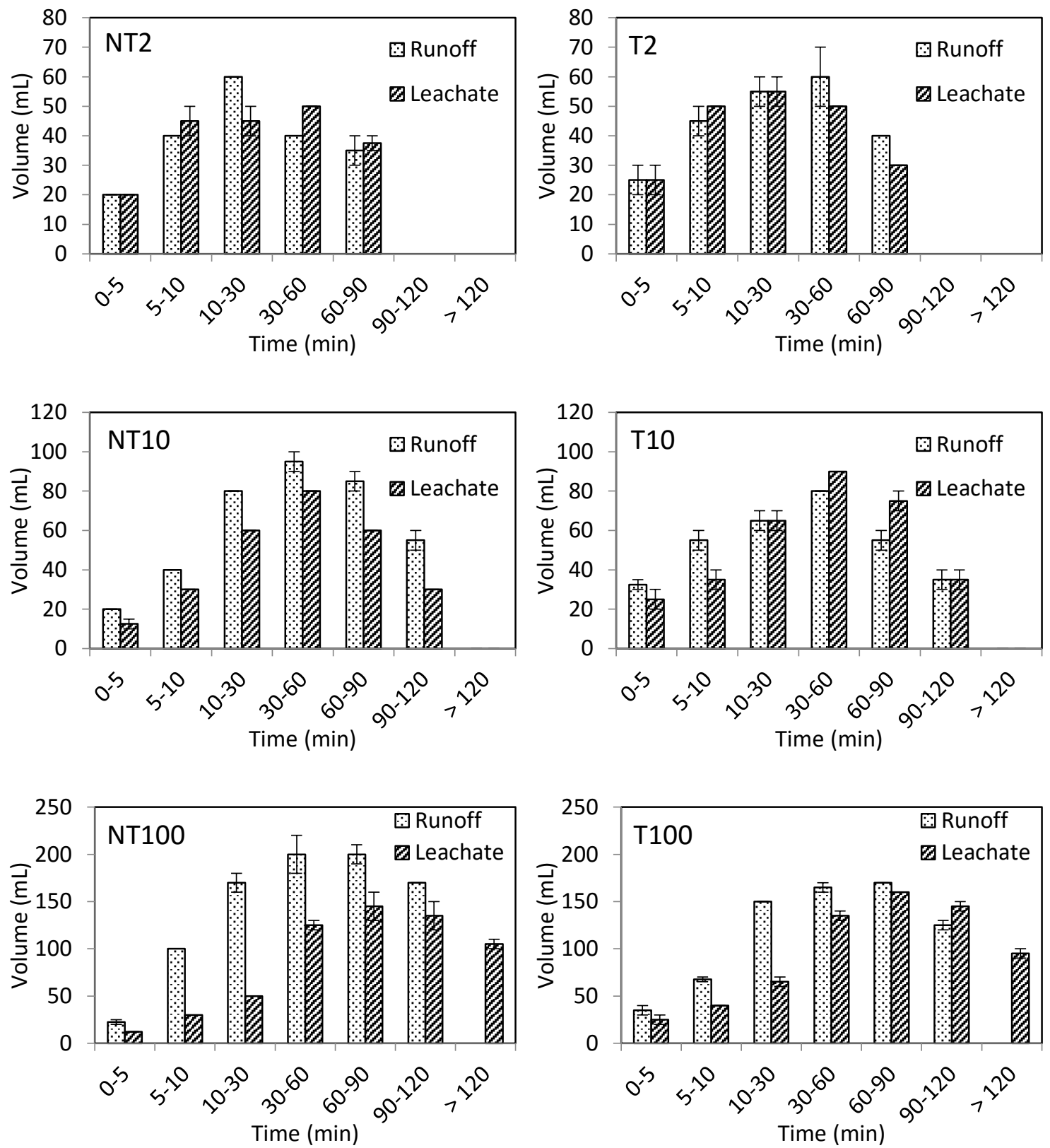

Figure 2. Volume (mL) of samples collected in runoff and leachate at different time intervals under six different operation conditions. Definitions of NT2, T2, NT10, T10, NT100, and T100 are shown in Table 1 (e.g., NT2 = No tillage with 2 years return frequency; $\mathrm{T} 2=$ Tillage with 2 years return frequency). Error bars indicate the standard deviation of two results from the two parallel chambers. 


\section{Figure 3}
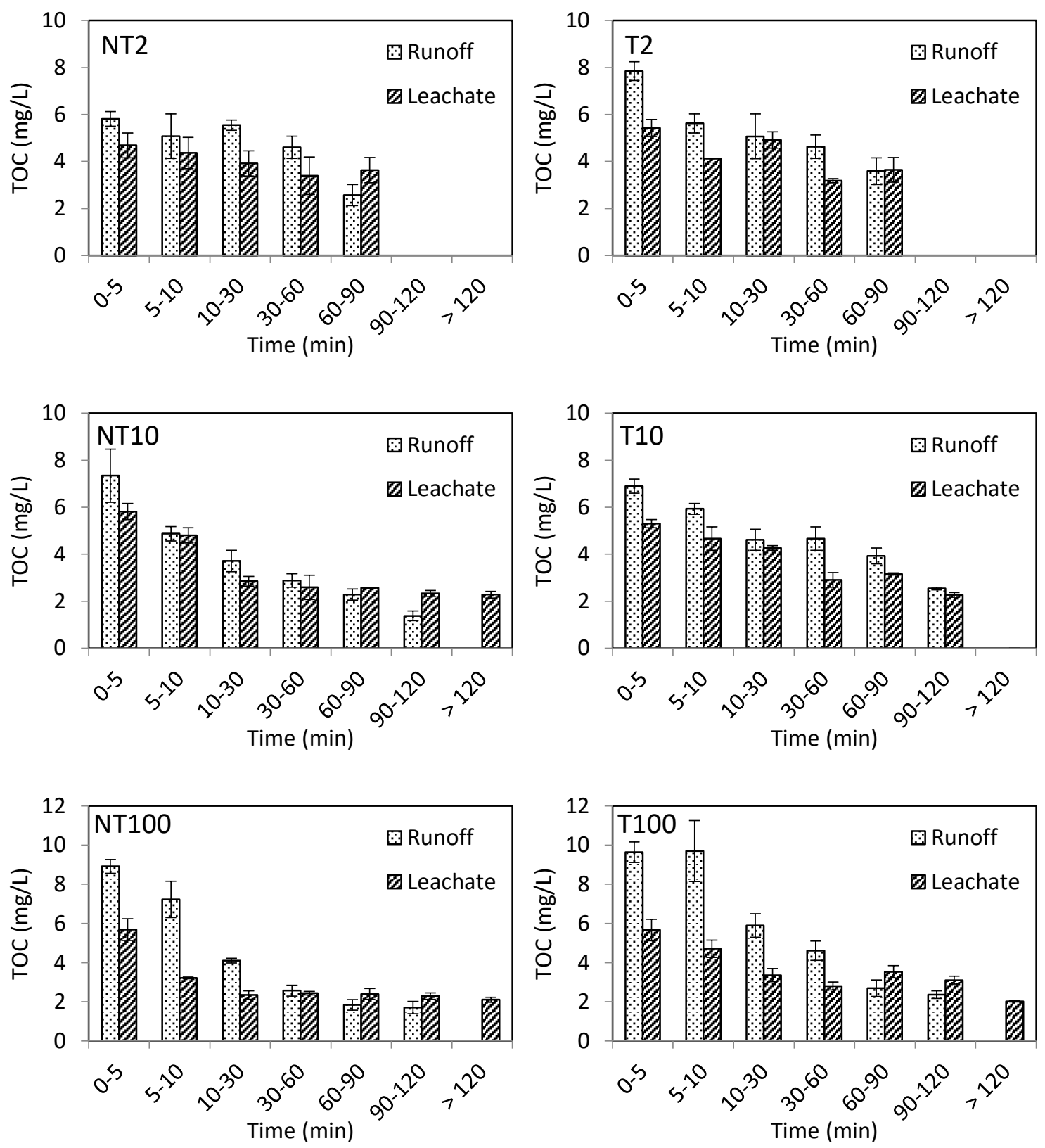

Figure 3. Total organic carbon (TOC) $(\mathrm{mg} / \mathrm{L})$ of collected runoff and leachate at different time intervals under six different operation conditions. Definitions of NT2, T2, NT10, T10, NT100, and T100 are shown in Table 1. Error bars indicate the standard deviation of two results from the two parallel chambers. 


\section{Figure 4}
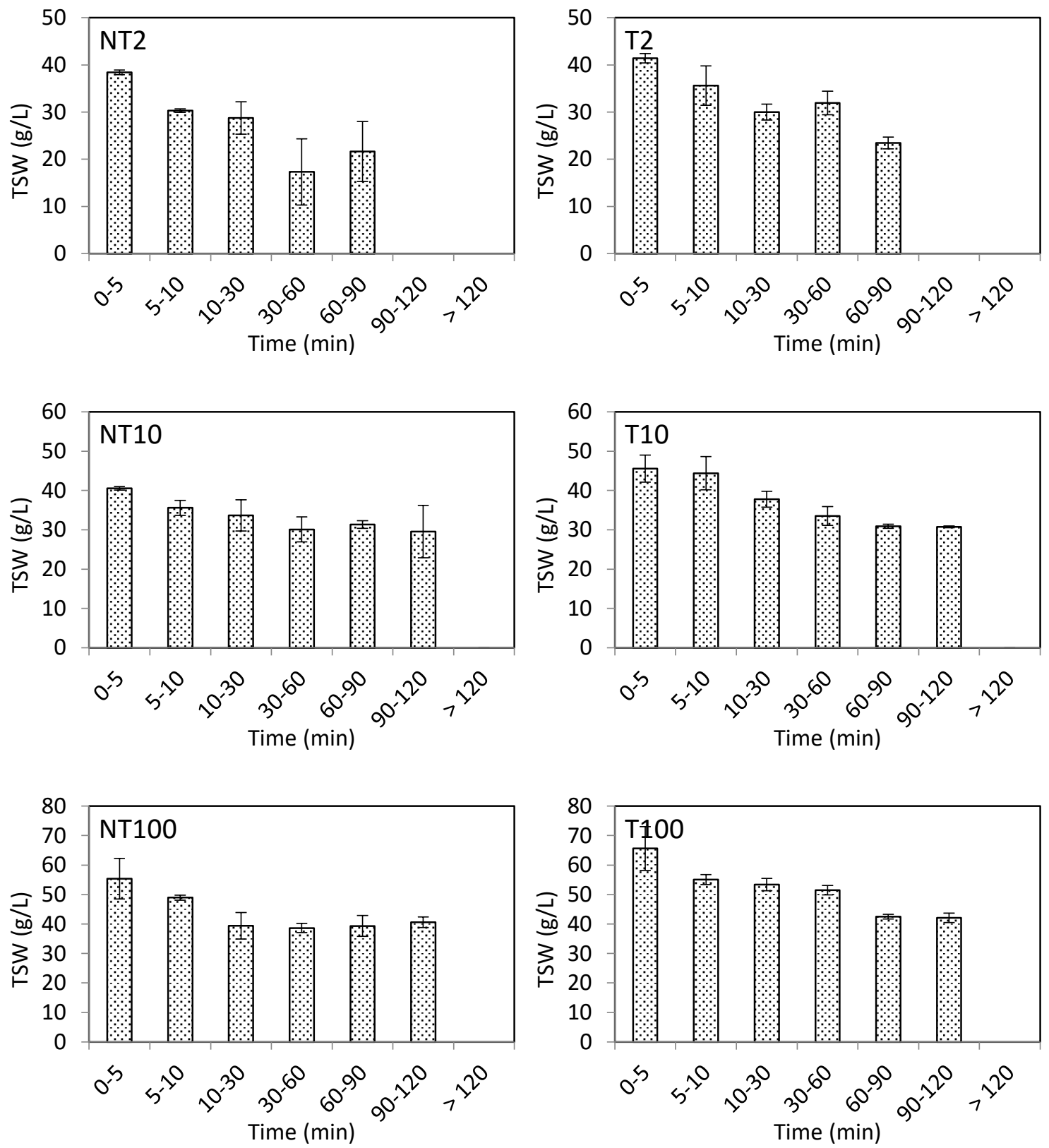

Figure 4. Transported soil weight (TSW) taken away by runoff at different time intervals under six different operation conditions. Definitions of NT2, T2, NT10, T10, NT100, and T100 are shown in Table 1. Error bars indicate the standard deviation of two results from the two parallel chambers. 


\section{Figure 5}
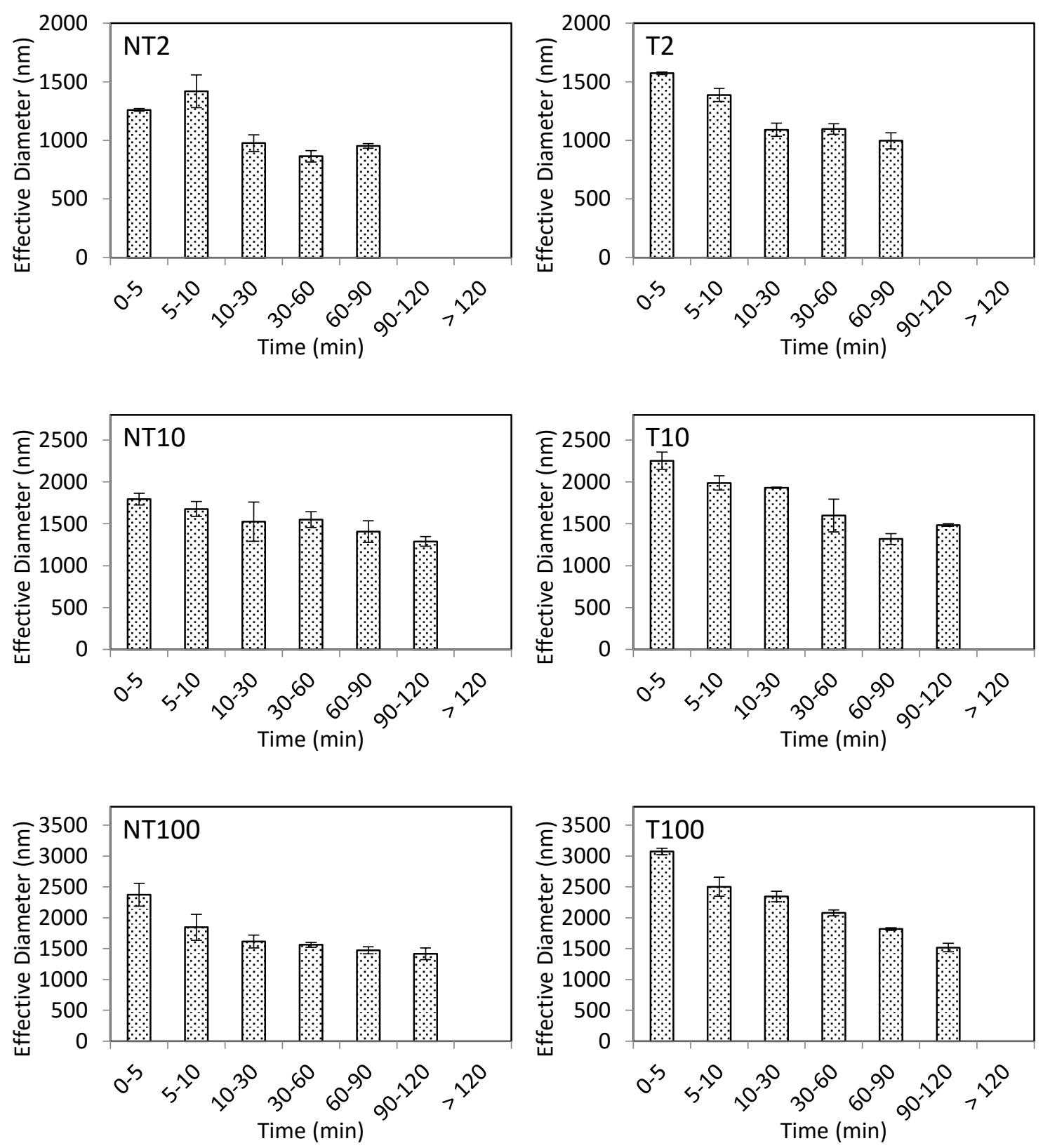

Figure 5. Effective diameter (nm) of the soil particles taken away in runoff and leachate at different time intervals under six different operation conditions. Definitions of NT2, T2, NT10, T10, NT100, and T100 are shown in Table 1. The soil slurry was wet sieved with No.200 sieve $(0.75 \mu \mathrm{m})$ before being measured with particles size analyzer (NanoBrook 90Plus/BI-MAS, Brookhaven Instrument Corp). Error bars indicate the standard deviation of two results from the two parallel chambers. 


\section{Figure 6}
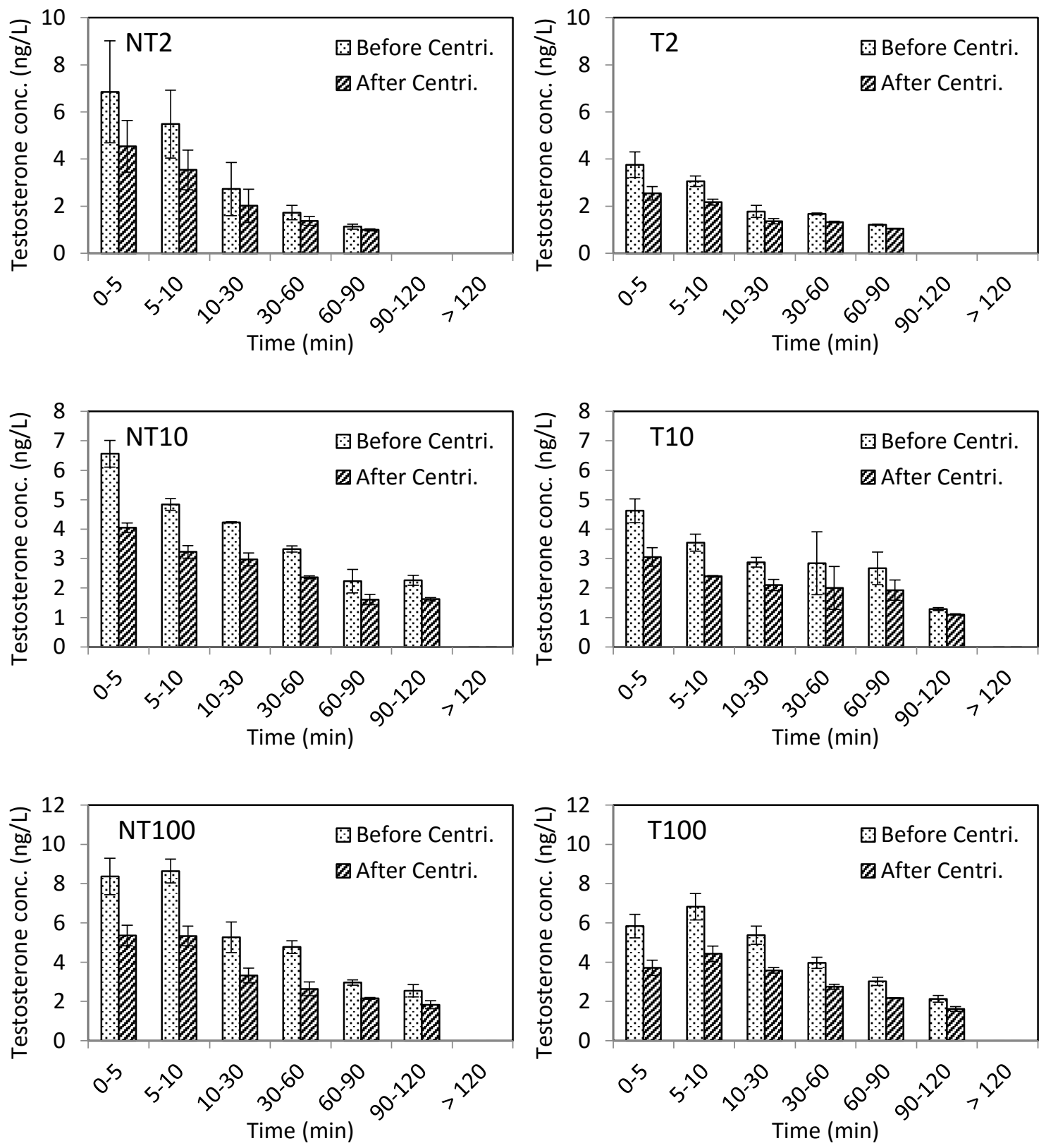

Figure 6. Testosterone concentration (ng/L) before and after centrifugation (4000 rpm for 45 min) of the collected runoff slurry samples at different time intervals under six different operation conditions. Definitions of NT2, T2, NT10, T10, NT100, and T100 are shown in Table 1. The difference of the testosterone concentration before and after centrifugation was contributed by the testosterone sorbed by soil particles. Error bars indicate the standard deviation of two results from the two parallel chambers. 


\section{Figure 7}

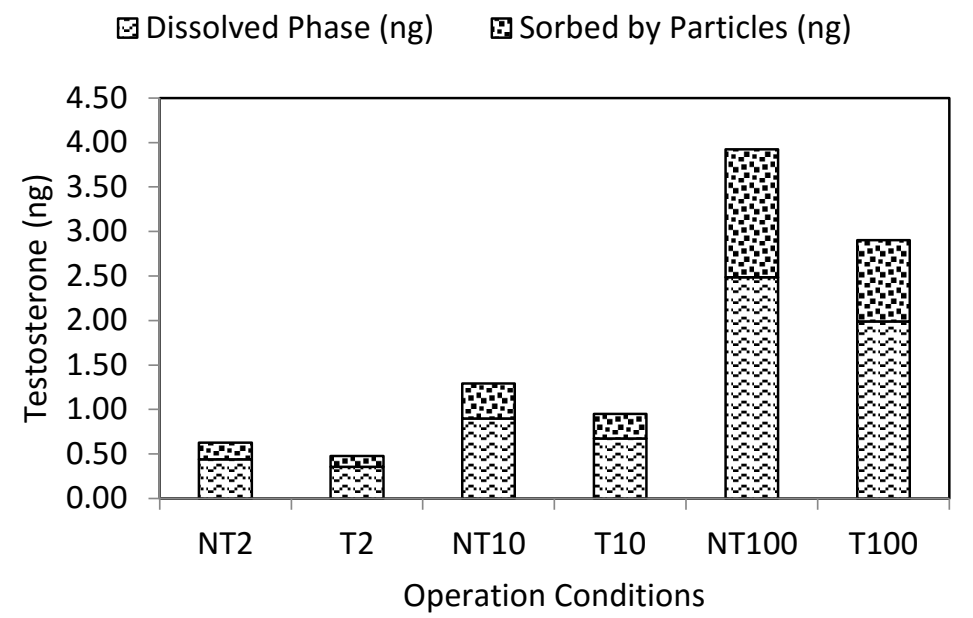

Figure 7. Testosterone mass distributions in the dissolved and particle-associated phases in runoff under six different operation conditions. 
Graphic Abstract:

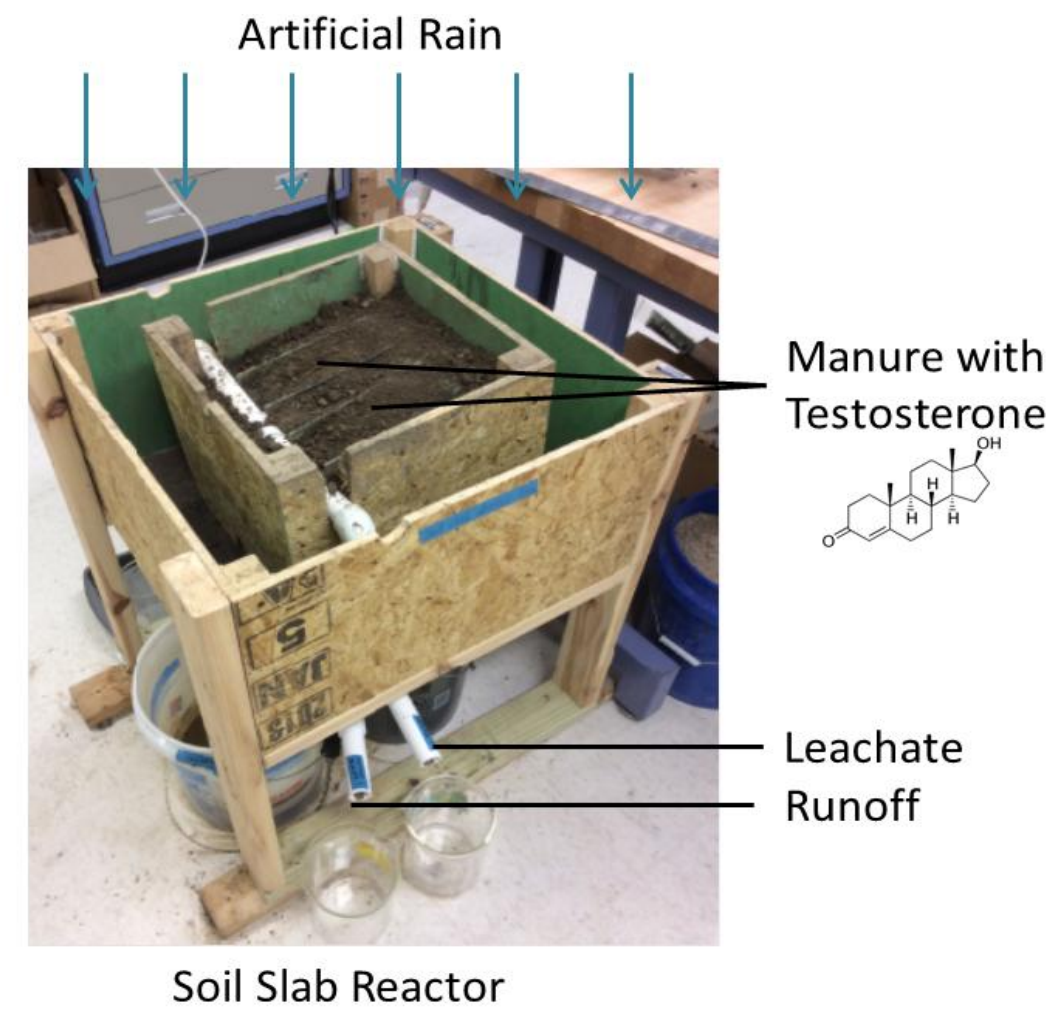

